\title{
ESPAÇOS PÚBLICOS DE PROPRIEDADE PRIVADA: OS POPS DE NOVA YORK
}

\author{
PRIVATELY OWNED PUBLIC SPACES: POPS IN NEW YORK
}

\author{
Luciana Oliveira* \\ Maria Augusta Justi Pisani**
}

\section{RESUMO}

Este artigo discute as implicações da transferência de responsabilidade da proposição e gestão dos espaços coletivos, da esfera pública para a esfera privada, e qual o impacto e/ou contribuição dessa transferência para a paisagem urbana e a qualidade de vida. $\bigcirc$ objeto de estudo é o sistema de bonificação utilizado em Nova York para criação de espaços de propriedade privada de uso coletivo, denominados POPS (Privately Owned Public Spaces). A pesquisa realizou levantamento quantitativo e qualitativo com base nos preceitos teóricos de Jan Gehl (2006), na Park Avenue. Os resultados obtidos demonstraram que as praças corporativas dos edifícios contribuem para o sistema de espaços livres para uso público e enobrecem a paisagem urbana local. Porém, a apropriação dos espaços livres pela população depende do grau de acessibilidade e permeabilidade visual entre os POPS e as circulações públicas, as calçadas.

Palavras-chave: Espaços públicos de propriedade privada. Paisagem urbana. Espaço público.

\section{ABSTRACT}

This article discusses the implications of transferring the provision and management of collective public places from the public to the private sphere as well as the impact and/or contribution of this transference to the urban landscape and the citizens' quality of life. The subject of this study is the bonus system adopted in New York City to create privately owned spaces for public use, known as POPS (Privately Owned Public Spaces). Based on Jan Gehl's theoretical principles, a quantitative and qualitative survey on Park Avenue was carried out. The analysis of the collected data showed that buildings' corporate plazas not only contribute to public use of free spaces but also ennoble the urban landscape of the area. Yet, people's effective use of these open public spaces still depend on the degree of accessibility and visual permeability between the POPS and the public circulation areas, the sidewalks.

Keywords: Privately owned public spaces. Urban landscape. Public space.

\section{INTRODUÇÃO}

As cidades são estruturadas a partir dos arranjos entre os espaços públicos e privados. A configuração espacial dessa divisão é determinada pelos contextos cultural, econômico, temporal e territorial de cada sociedade, impactando diretamente a vida social dos cidadãos e a formação da paisagem urbana local. Com relação ao impacto

\footnotetext{
* Universidade Presbiteriana Mackenzie, Faculdade de Arquitetura e Urbanismo. Rua da Consolação, 930, CEP 01302-907, Consolação, São Paulo, SP. CV: http://lattes.cnpq.br/4466485917049814 
na vida social, Madanipour (2003, p. 2) afirma: "O modo como o espaço é subdividido e a relação entre a esfera pública e privada, em geral são um espelho das relações sociais e um indicador principal de como a sociedade se organiza.".

Além da questão da propriedade do solo, outro tema que envolve os espaços públicos e privados está relacionado à possibilidade ou permissibilidade de uso, podendo ser este individual, para grupos restritos, ou para uso coletivo - com acesso à população em geral:

A riqueza civil e arquitetônica, urbanística e morfológica de uma cidade, são seus espaços coletivos, todos os lugares onde a vida coletiva se desenvolve, representa e recorda. Talvez estes sejam, cada dia mais, os espaços que não são nem públicos nem privados, se não ambos ao mesmo tempo. Espaços públicos absorvidos por usos particulares, ou espaços privados que adquirem uma utilização coletiva (SOLÀ-MORALES, 2001, p. 104).

Dietmar Steiner (2004 apud CAMPOS, 2004, s/p) aponta que a diferença entre espaço público e coletivo está no "[...] caráter socializado da concepção do espaço público que representa o direito público; mas é no espaço coletivo que se marca a identidade através do uso e da acessibilidade que as pessoas dão a estes espaços".

Os espaços coletivos das cidades são, portanto, os espaços que possibilitam o encontro dos cidadãos, e podem ser ambientes abertos - como ruas, calçadas, praças e parques - ou ambientes construídos, como as edificações para atividades esportivas, culturais, educacionais, religiosas e comerciais.

A United Nations Human Settlements Programme (UN-HABITAT) aprovou em 2001 a resolução sobre os objetivos do desenvolvimento urbano sustentável, na qual destaca a importância do acesso a espaços públicos urbanos de qualidade. Estes reforçam os vínculos das comunidades, melhoram a segurança, promovem a coesão e igualdade social, melhoram a saúde e o bem-estar dos cidadãos, fomentam a economia e promovem a sustentabilidade ambiental. Outra característica que tem se apresentado nos espaços públicos contemporâneos projetados e geridos de forma consistente, é o fato de tornarem as cidades mais inspiradoras e promoverem a mobilidade mais eficiente (UN-HABITAT, 2015).

Para Goldberger (2007), atualmente, tanto nas cidades quanto nos subúrbios intensifica-se cada vez mais a transferência das funções que antes eram dos espaços públicos - o encontro de pessoas para fins comerciais ou cívicos - para espaços privados fechados, como shopping centers, casas de espetáculos culturais, áreas comuns de hotéis, lobbies de cinemas multiplex e teatros, pavimentos térreos de edifícios multifuncionais; e para espaços privados abertos - praças corporativas e parques temáticos. Tais espaços privados substituem as funções dos espaços públicos, das ruas, mercados, praças e parques.

A existência e a proliferação de espaços para uso coletivo em propriedades privadas são uma prova de que a sociedade contemporânea ainda não desistiu do desejo de proximidade física com os outros em um local compartilhado - papel dos espaços 
públicos - mesmo que em ambientes muito diferentes das ruas tradicionais. Goldberger afirma que, sob a alegação da escassez de recursos até para a manutenção dos locais públicos já existentes, algumas cidades transferiram para o setor privado a criação de novos espaços para uso público (GOLDBERGER, 2007). Despontaram, então, algumas tipologias no urbanismo a partir do incentivo proposto pelos códigos de zoneamento para a criação de espaços de uso público dentro de edifícios de propriedade privada, como átrios e galerias de edifícios de escritórios.

O modo como a configuração espacial decorrente da divisão entre os espaços públicos e privados determina a paisagem urbana é uma consequência da ação direta ou indireta do estado. Segundo Macedo (2012, p. 86):

O Estado, de um modo direto ou indireto, é o principal agente condicionador e formador de espaços livres. Sua ação se dá tanto por intermédio da implementação de normas legais que direcionam o mercado imobiliário e a população na constituição dos assentamentos urbanos como também na produção e gestão de espaços públicos, como praças, parques, avenidas, áreas de proteção ambiental etc.

De acordo com Macedo (2012), as ações diretas materializadas pelo poder público são facilmente identificáveis, como o conjunto de obras para o sistema viário e a circulação de pedestres, e envolvem predominantemente os espaços de propriedade pública. As ações indiretas, por sua vez, compreendem o conjunto de restrições legislativas e urbanísticas implantadas pelas políticas públicas e pelos órgãos públicos, e impactam as paisagens urbanas, atuando tanto na configuração das áreas de propriedade pública quanto nas áreas de propriedade privada:

A ação indireta se expressa em todo o aparato legal da legislação, ambiental ou urbanística, que age de uma forma incisiva pela cidade, disciplinando as ações da população e dos órgãos públicos, induzindo a configuração de suas paisagens, tanto no desenho dos arruamentos, como no dimensionamento dos lotes, na limitação da altura das construções, na criação de estoques de áreas livres públicas para a construção de parques e praças, denominadas legalmente de "áreas verdes", nos recuos dos edifícios, na criação de áreas de proteção ambiental etc. (MACEDO, 2012, p. 86).

Este artigo aborda uma ação indireta do poder público municipal, utilizada por algumas cidades dos Estados Unidos da América (EUA), como Nova York, Boston, San Francisco, que afeta diretamente a configuração espacial e, portanto, a vida social dos cidadãos e a paisagem urbana. Trata-se do sistema de bonificação que incentiva a criação de espaços de uso público dentro de lotes de propriedade privada, denominados Privately Owned Public Spaces (POPS). A cidade de Nova York foi pioneira na utilização desse sistema a partir da promulgação da Resolução de Zoneamento de 1961.

A proposição do sistema de bonificação foi justamente uma resposta do poder público municipal diante da necessidade da melhoria da qualidade urbana de áreas 
adensadas e verticalizadas da cidade, visando à melhor insolação e aeração das ruas e calçadas e o aumento de áreas para uso público nas regiões valorizadas da cidade.

Baneriee (2007) já havia identificado a pequena expansão na proposição de parques e sistemas de espaços livres nas grandes cidades dos EUA nas últimas décadas, principalmente quando comparada ao crescimento de um século atrás. A criação de espaços livres não está acompanhando o crescimento da população, e há desigualdade na distribuição dos espaços livres urbanos quando comparada as áreas verdes dos condomínios de classe média e alta, nas áreas mais afastadas, e as áreas densamente ocupadas das zonas centrais das cidades.

A metodologia aqui utilizada visa à análise do impacto dos espaços públicos de propriedade privada (POPS) na paisagem urbana de área de centralidade verticalizada e adensada, utilizando como objeto de análise um setor de Midtown, em Manhattan. A relevância desta pesquisa pode ser inicialmente considerada local, por tratar-se do exame das qualidades dos espaços públicos de uma centralidade da cidade de Nova York. Contudo, sob uma perspectiva abrangente, pode ser subsídio para estudos similares em cidades que melhoraram qualitativamente segmentos de seu tecido urbano e trouxeram melhorias para a população em geral. É o caso, por exemplo, de Barcelona, Londres, Nova York e Chicago, que apresentaram aumento na procura pelo turismo local a partir de investimentos pontuais em setores das cidades.

São os espaços públicos que dão nexo para as cidades. A qualidade desses espaços é diretamente proporcional à qualidade de vida na cidade, fazendo a conexão e a transição entre os outros espaços, dos restritamente privados aos integralmente públicos, sendo a paisagem urbana composta por essas mesclas de propriedades e usos. Estudá-los permite entender a qualidade da cidade e a qualidade de vida dos cidadãos.

O objetivo principal desta pesquisa é contribuir para a discussão sobre o processo de privatização dos espaços para uso coletivo em áreas de centralidades por meio do estudo e análise de um fragmento urbano de Nova York, e auxiliar na promoção de diretrizes a serem adotadas pelas políticas públicas urbanas com relação às áreas para uso público, além da melhoria e valorização paisagística das cidades brasileiras.

Primeiramente apresenta-se um breve histórico das Resoluções de Zoneamento de Nova York, uma vez que a história dos POPS está diretamente relacionada aos avanços da legislação. Em seguida, é traçado um panorama da situação atual dos POPS de Nova York, e finalmente utiliza-se do estudo de caso de um trecho da Park Avenue para apresentar os resultados quantitativos e qualitativos, que permitem analisar o impacto dos espaços públicos de propriedade privada sobre a paisagem urbana de uma área verticalizada e adensada da cidade.

\section{AS RESOLUÇÕES DE ZONEAMENTO DE NOVA YORK}

A cidade de Nova York pertence à porção sul do estado de Nova York, região nordeste dos Estados Unidos, e está dividida em cinco distritos: Brooklyn, Bronx, Manhattan, Queens e Staten Island. Nova York faz parte de um arquipélago na foz do 
rio Hudson; somente o distrito do Bronx está no continente. A ilha de Manhattan é o centro econômico da cidade e o mais densamente habitado, com 26.876,20 habitantes por $\mathrm{km}^{2}$ e 1.585.873 habitantes, segundo o levantamento demográfico de 2010 (U.S. CENSUS BUREAU, 2010).

A cidade é um exemplo dos mais significativos do tipo de parceria público-privada como forma de obtenção de capital para investimento na criação de espaços públicos de propriedade privada. Os POPS são definidos como os espaços para uso público, criados e mantidos por empreendedores em troca de uma área adicional de construção (ZONING Resolution, 2012). A partir da Resolução de Zoneamento de 1961, os edifícios residenciais e de escritórios puderam obter uma bonificação em área construída em troca da criação de espaços de uso público em seus empreendimentos. Os espaços poderiam ser internos ou externos, compreendendo praças, galerias, átrios, desde que fossem acessíveis para o uso coletivo. Um dos primeiros objetivos da implantação dos POPS, a partir da implantação do Zoneamento de Incentivo', foi permitir melhor iluminação natural e aeração dos distritos de alta densidade comercial e residencial, para amenizar o caráter predominantemente rígido e verticalizado das áreas mais densas da cidade.

Desde o primeiro decreto de zoneamento dos EUA - a Resolução de Zoneamento de 1916, promulgada na cidade de Nova York -, implantou-se restrições para limitar e regulamentar a altura e os volumes das edificações, com o objetivo de aumentar as áreas livres entre os edifícios para melhorar a aeração e insolação no nível dos térreos e calçadas (KAYDEN, 2000). Afinal, a cidade já estava em processo de verticalização desde o fim dos anos 1890 e início dos anos 1900, com a construção de edifícios que ocupavam todo o limite do lote. A associação entre os avanços tecnológicos dos elevadores de passageiros e das estruturas metálicas utilizadas na construção dos edifícios ampliou significativamente o número de pavimentos que podiam atingir.

$\mathrm{Na}$ Thames St, no Financial District, é possível observar a pequena área de céu visível a partir da rua estreita entre o edifício 111 Broadway, inaugurado em 1905, e o edifício 115 Broadway, inaugurado em 1907, ambos com 21 pavimentos e ocupando praticamente o lote inteiro, sem recuos (figuras 1 e 2).

De acordo com Kayden (2000), para evitar o afunilamento das ruas, a Resolução de Zoneamento de 1916 introduziu restrições de gabarito que limitaram a altura do edifício no alinhamento do lote. Em alguns setores da cidade, por exemplo, a altura máxima do edifício no alinhamento do lote era de duas vezes e meia em relação à largura da rua, e, a partir desse limite, o edifício deveria obedecer a recuos que permitiam aumentar sua altura total. Essa restrição legislativa levou a uma configuração de escalonamentos conforme os edifícios verticalizavam, que recebeu a alcunha de "bolo de noiva", ou de "zigurate", e criou um perfil de paisagem repleto desse efeito em trechos da cidade (figura 3).

Z Zoneamento de Incentivo foi assim denominado em decorrência da política pública inserida na Resolução de Zoneamento da Cidade de Nova York, de 1961, que fomentou a criação de espaços de uso público em propriedades privadas a partir da premissa de incentivar, ao invés de exigir, que os incorporadores privados atuassem segundo as intenções do poder público (KAYDEN, 2000, p. 11). 


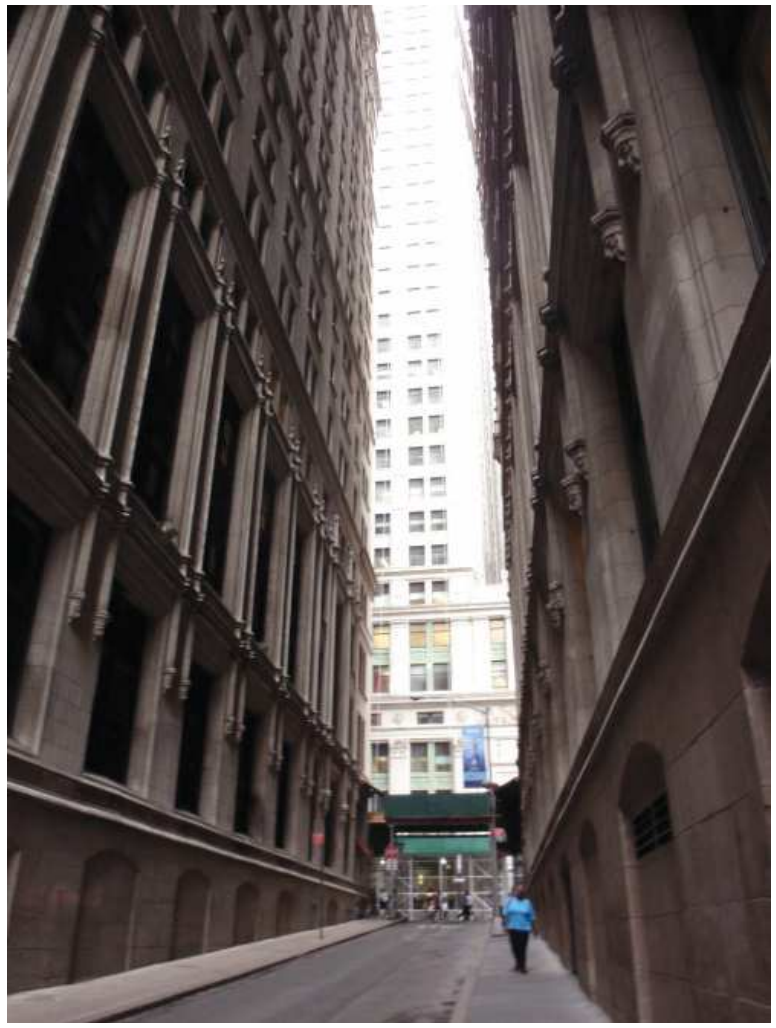

Figura 1 Thames St, no Financial District, Nova York.

Foto: Luciana Monzillo de Oliveira, 2013.
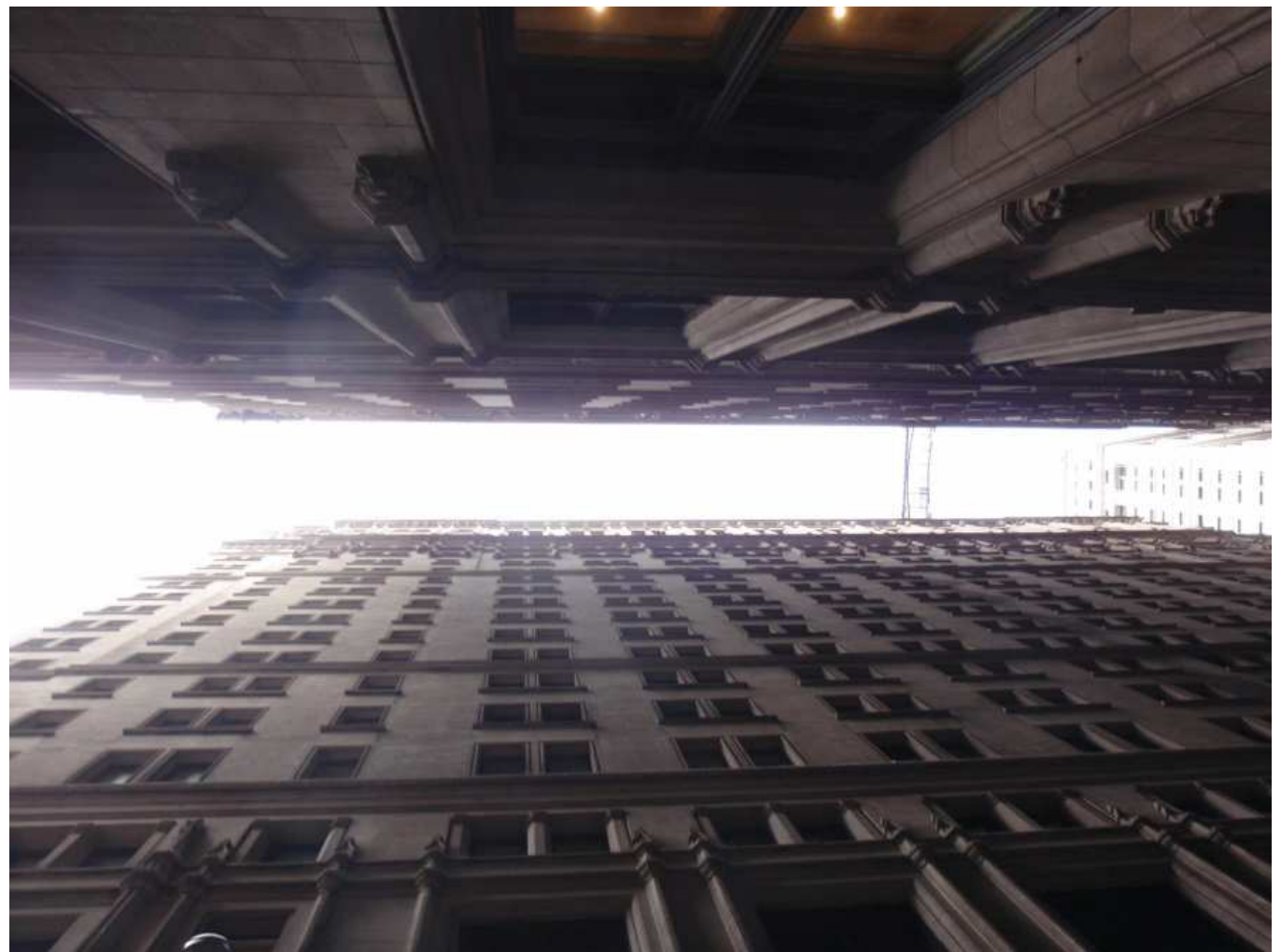

Figura 2 Céu visível a partir do centro da Thames St, no Financial District, Nova York. Foto: Luciana Monzillo de Oliveira, 2013. 


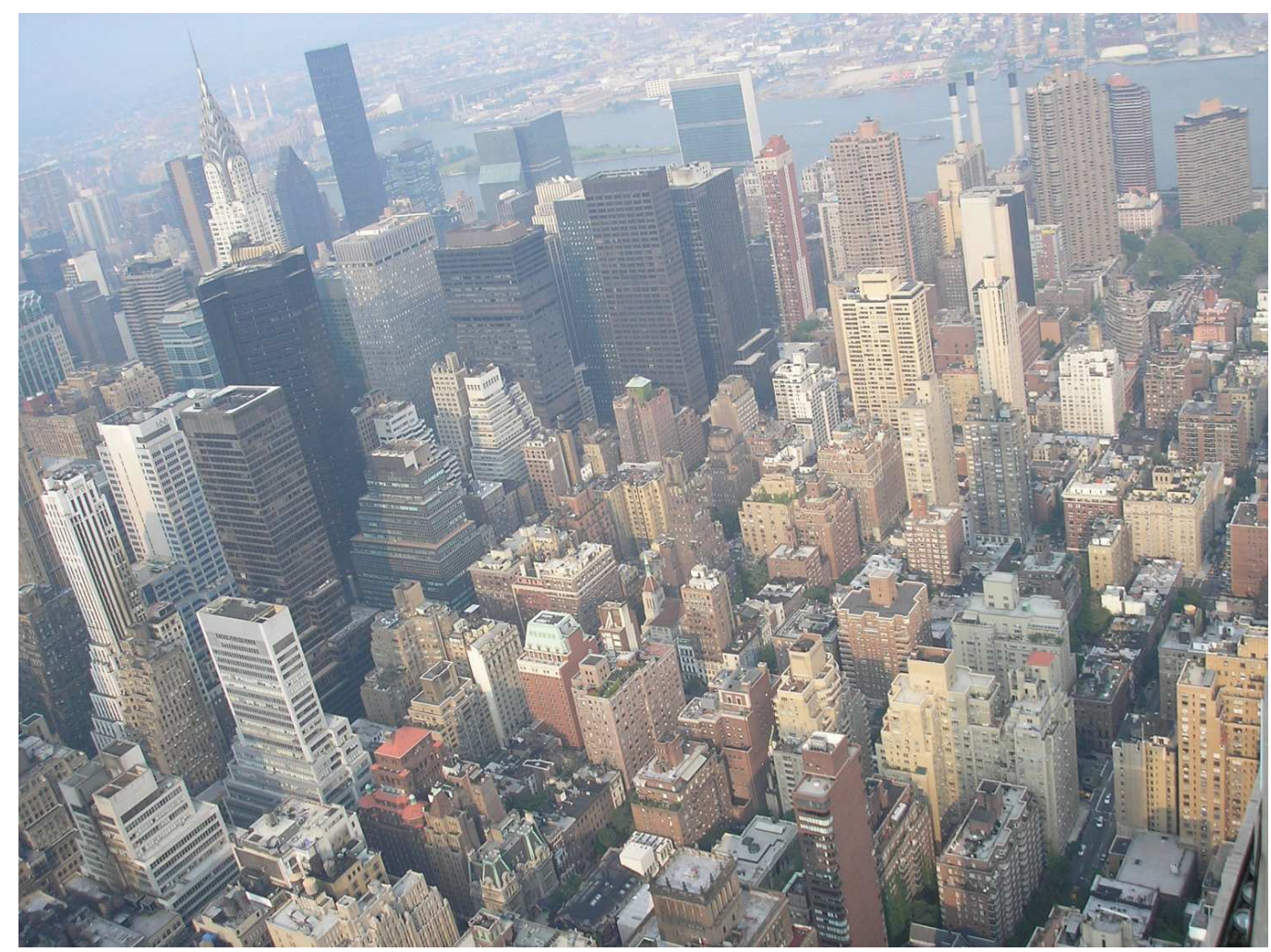

Figura 3 Vista aérea do lado leste de Manhattan, que contém muitos edifícios com formato escalonado, em decorrência das restrições urbanísticas da Resolução de Zoneamento de 1916.

Foto: Luciana Monzillo de Oliveira, 2013.

Outra restrição urbanística da Resolução de Zoneamento de 1916 indicava que toda porção de edifício que ocupasse apenas $25 \%$ da área do terreno e o fundo do lote poderia verticalizar sem restrições de gabarito. Tal tipologia não teve grande aceitação do mercado em função dos custos necessários para viabilizar os empreendimentos, mas foram construídas algumas exceções como o Empire State Building (1931) e o Chrysler Building (1930), que utilizaram quase toda a base do terreno nos níveis inferiores e depois afinaram a porção superior.

Dois edifícios foram fundamentais para a revisão da legislação: o Lever House e - Seagram Building, ambos nas esquinas opostas da Park Avenue com a E57th St. De tipologias diferentes dos "bolos de noiva", esses edifícios serviram de inspiração para as novas restrições urbanísticas que foram adotadas na Resolução de Zoneamento de 1961. O edifício Lever House (1952), projetado por Skidmore, Owings \& Merril LLP (SOM), tem embasamento em bloco horizontal que ocupa quase todo o lote, suspenso do pavimento térreo, criando uma praça coberta com passagem livre entre as ruas e uma torre disposta perpendicularmente à avenida (figuras 4 e 6). Já o Seagram Building (1958), projeto de Mies Van der Rohe, é uma torre única, recuada ao fundo do lote, criando uma praça frontal com dois espelhos d'água (figuras 5 e 7).

As novas configurações volumétricas e de implantação do Lever House e o Seagram Building serviram de referência para as propostas de reformulação da legislação de 
Nova York, formuladas pelo escritório de arquitetura Voorhees Walker Smith \& Smith, contratado pela prefeitura. A Resolução de Zoneamento de 1961 introduziu duas novas restrições urbanísticas importantes para a mudança do perfil da paisagem de Nova York. Uma delas foi a introdução do Coeficiente de Aproveitamento (FAR), índice que estabelece a área total de construção em função da área do terreno. Outra restrição foi a introdução de novo método para estabelecer os recuos das edificações, que não mais seriam em função da largura da rua, mas o estabelecimento de uma altura máxima para o embasamento do edifício no alinhamento do lote (KAYDEN, 2000). As novas regras impulsionaram a construção de edifícios com embasamentos menores, torres mais altas, e por vezes uniformes, que não apresentam base expandida no nível do térreo, permitindo maiores áreas livres de edificações dentro dos lotes.

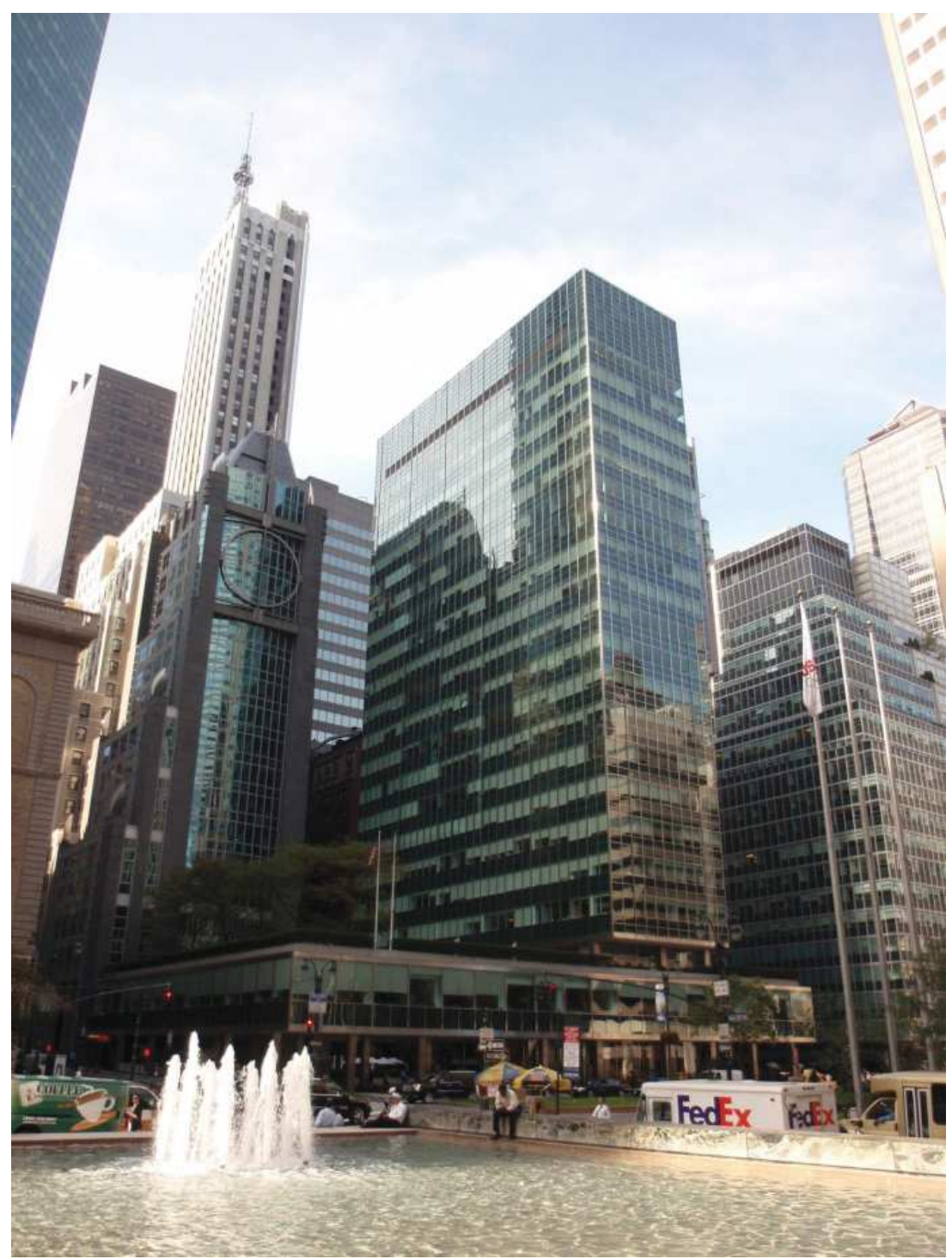

Figura 4 Edifício Lever House, Park Avenue.

Foto: Luciana Monzillo de Oliveira, 2013. 


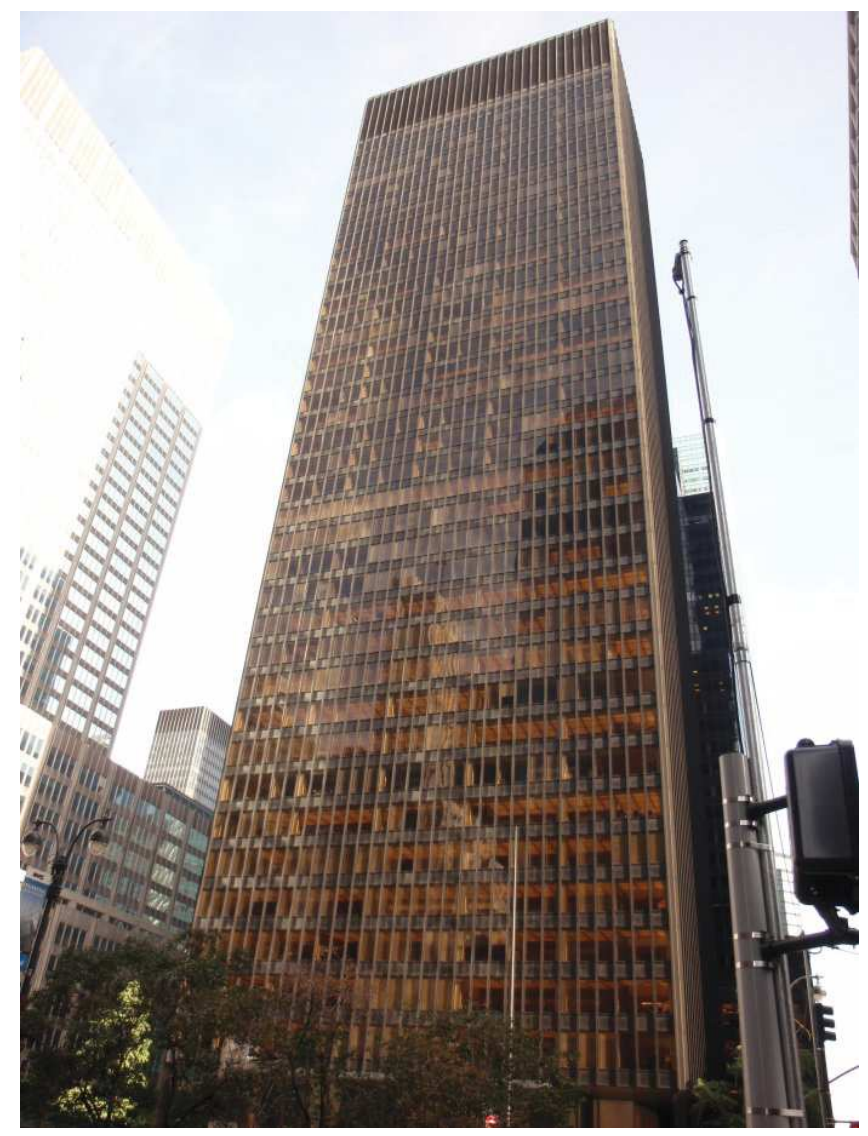

Figura 5 Seagram Building,

Park Avenue.

Foto: Luciana Monzillo de Oliveira, 2013.

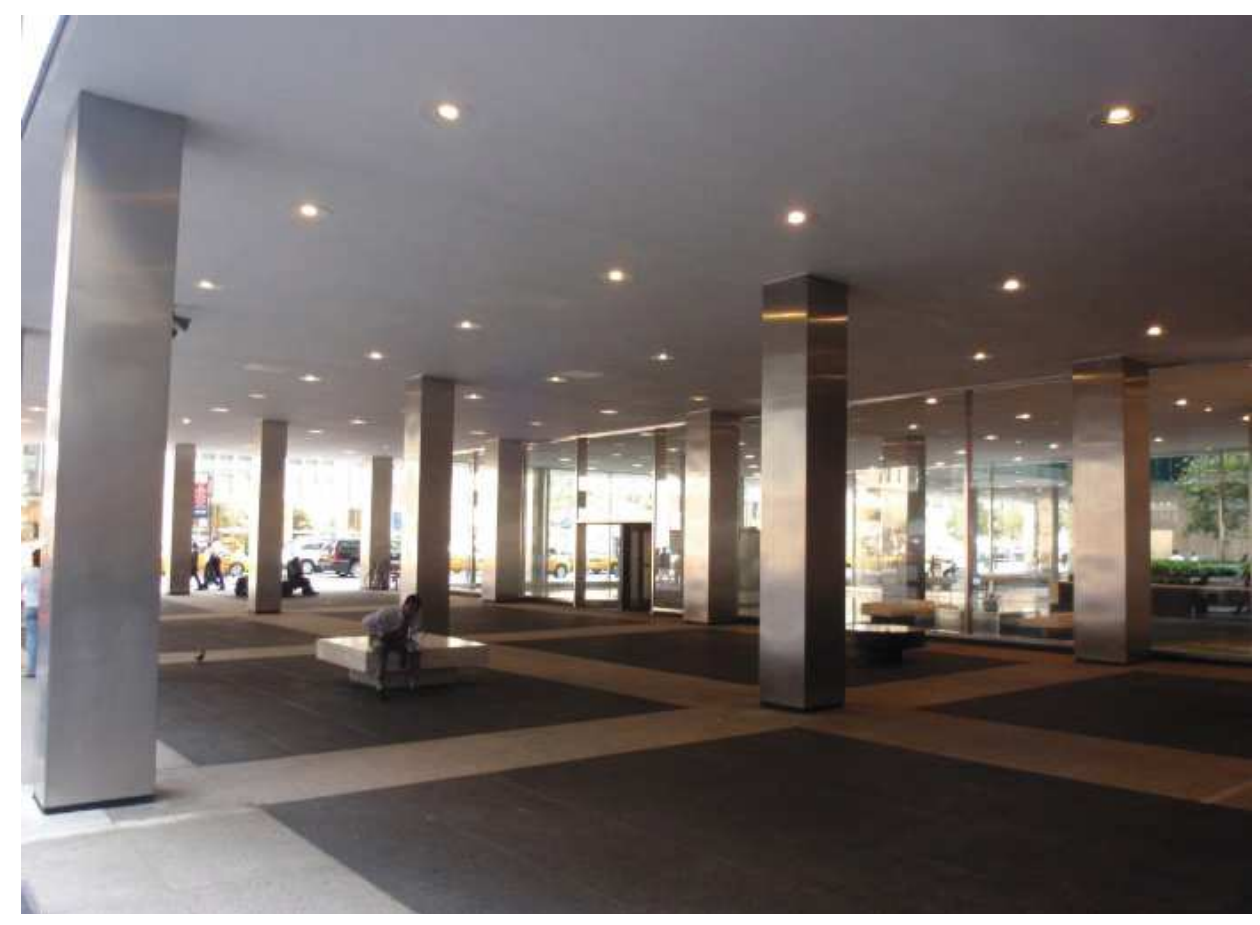

Figura 6 Marquise do edifício Lever House, Park Avenue. Foto: Luciana Monzillo de Oliveira, 2013. 


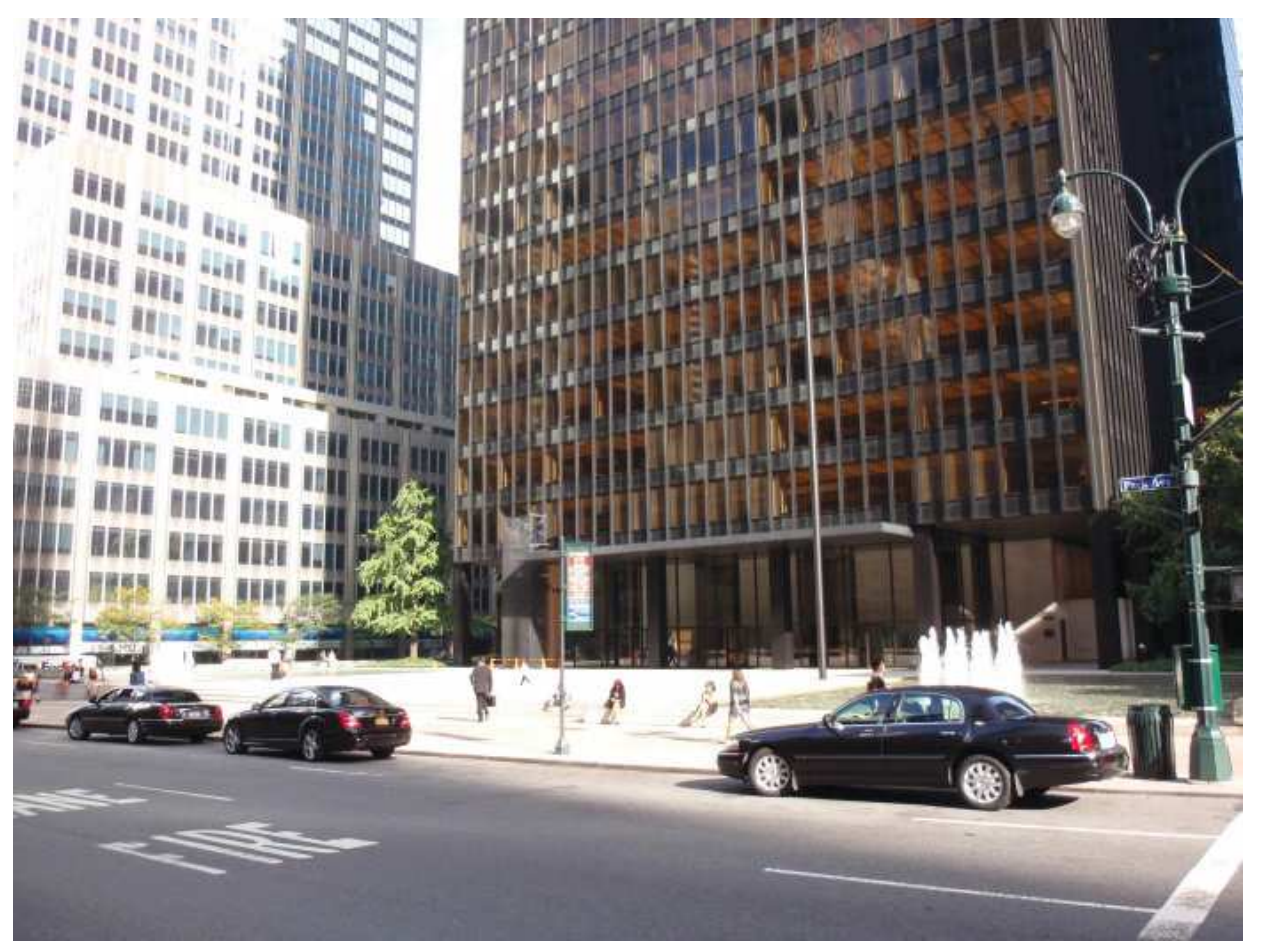

Figura 7 Praça do Seagram Building, Park Avenue. Foto: Luciana Monzillo de Oliveira, 2013.

Além das novas restrições urbanísticas, a Resolução de Zoneamento de 1961 introduziu um sistema de bonificação para incentivar o empreendedor privado a atuar em parceria com o setor público para a criação de espaços de uso coletivo, dando origem às regras dos POPS. A princípio, a resolução permitia alguns tipos de espaços, como praças e galerias, mas com o decorrer do tempo foram permitidos o alargamento de calçadas e as marquises.

Os POPS estão concentrados, em sua maioria, nas áreas verticalizadas do distrito de Manhattan, onde o espaço público é muito valorizado, devido à sua escassez nos bairros Upper East Side, Upper West Side, Midtown e no sul da ilha, em Lower Manhattan. Nos distritos do Brooklyn e do Queens, há poucas unidades, e nos distritos do Bronx e Staten Island não há nenhum POPS.

A contrapartida, em forma de bonificação para a implantação de espaços de uso público, mostrou-se irresistível para a maioria dos empreendedores de edificações residenciais e de escritórios. Kayden relata que dos 95 edifícios comerciais construídos entre 1966 e 1975 que poderiam utilizar o sistema, 67 edificações, ou seja 79\% do total, o fizeram (KAYDEN, 2000).

Em função da desigualdade entre as qualidades dos espaços criados, o Departamento de Planejamento da Cidade de Nova York criou, no início dos anos 1970, uma equipe de designers, planejadores e advogados para elaborar um Estudo do Espaço Urbano Aberto, com a participação de conselhos comunitários locais. $\bigcirc$ trabalho desenvolvido pela equipe baseou-se na pesquisa desenvolvida por William $\mathrm{H}$. Whyte, denominada 
Street Life Project, que levou à proposição de alterações na Resolução de Zoneamento e estipulou equipamentos mínimos e obrigatórios a serem instalados nos novos POPS, como assentos, áreas verdes, bicicletários, bebedouros e placas de identificação.

Em 21 de maio de 1975, a cidade aprovou uma emenda na Resolução de Zoneamento, implementando a primeira grande revisão no sistema de bonificação e impondo padrões mais rigorosos de projeto, com o objetivo de garantir as qualidades necessárias para facilitar o acesso, o uso e a permanência das pessoas. A emenda também introduziu um procedimento administrativo que vinculava a liberação do bônus à aprovação do projeto detalhado do espaço, pela Comissão de Planejamento da Cidade, que reveria e certificaria para o Departamento de Edificações que o projeto proposto atendia aos novos padrões exigidos.

Mesmo com as melhorias resultantes a partir da emenda de 1975 e a nova forma de aprovação dos projetos, ainda surgiram exemplos de praças que não estimulavam o convívio dos usuários. Segundo pesquisa do final dos anos 1990, divulgada pela prefeitura de Nova York, aproximadamente 16\% dos espaços existentes até então eram utilizados como pontos de encontro do bairro; $21 \%$ eram utilizados como locais de repouso breve; $18 \%$ estavam relacionados com a circulação; $41 \%$ tinham pouca utilização (NEW YORK CITY, 2016).

Em razão desses dados e da insatisfação da população com alguns dos espaços, - Departamento de Planejamento da cidade, o Municipal Art Society e o professor de Planejamento Urbano da Universidade de Harvard, Jerold S. Kayden, desenvolveram uma nova pesquisa, que culminou no lançamento de um livro com um banco de dados sobre o assunto, o Privately Owned Public Space: the New York city experience. Os resultados obtidos demonstraram que parte dos espaços públicos criados pelo sistema de bonificação não apresentou qualidades suficientes ou equivalentes à quantidade de área construída a mais pelos empreendedores. Kayden observou que alguns desses espaços públicos de propriedade privada se mostraram problemáticos, parte deles tendo sido abandonados, descuidados e até privatizados.

No período entre 1961 e 2000, foram construídos 1.498.448,70 m² de espaço privado de uso comercial, serviços e residencial acima da área permitida pelas restrições urbanísticas, utilizando a Lei de Incentivo e fornecendo, como retorno, mais de quinhentas praças e galerias, que compreendem 323.748,36 $\mathrm{m}^{2}$ de espaço público de propriedade privada (APOPS, 2015). A pesquisa auxiliou o Departamento de Planejamento da cidade a ganhar experiência em compreender quais qualidades e padrões poderiam ajudar a criar espaços públicos bem-sucedidos a partir da análise de quais elementos básicos ou características de projeto incentivavam ou inibiam o uso público. Os problemas apresentados em alguns espaços foram parcialmente atribuídos à omissão, no texto da Resolução, de diretrizes e critérios mais específicos de projeto. Em compensação, o levantamento e análise dos espaços, principalmente das praças ao ar livre, demonstrou que havia vários exemplos de casos bem-sucedidos, que apresentavam elementos em comum, como áreas abundantes para assentos, canteiros de vegetações adequadas, boa acessibilidade e conforto para os usuários. 
Em função da pesquisa, em 17 de outubro de 2007, a Câmara Municipal aprovou uma emenda de texto, enviada pela Comissão de Planejamento da Cidade, relacionada aos padrões operacionais e de projeto dos POPS. As novas disposições tinham por objetivo atualizar os regulamentos para a implantação dos POPS e incentivar a criação de espaços públicos de melhor qualidade nas propriedades privadas. A emenda incluía:

- substituir as definições existentes de praça residencial e praça urbana para uma designação única, denominada praça pública;

- revisar e atualizar os padrões de projeto para as praças públicas a fim de assegurar projetos de qualidade em espaços abertos;

- consolidar as disposições relacionadas aos cafés e quiosques dentro das praças.

A emenda propôs alterações e nova padronização nos seguintes aspectos de projeto das praças: dimensão, configuração, localização no lote, orientação, visibilidade da praça, mudanças no nível, circulação e acesso, obstruções permitidas, assentos, canteiros e árvores, iluminação, lixeiras, estacionamento para bicicleta, sinalização e os usos em frente da praça. Também propôs alterações em relação ao funcionamento, incluindo o projeto de portões e barreiras para o fechamento noturno das praças, quiosques e cafés ao ar livre.

Em 17 de fevereiro de 2009, a Comissão de Planejamento Urbano (City Planning Commission) encaminhou nova emenda de texto à Resolução de Zoneamento, proposta pelo Departamento de Planejamento Urbano, sugerindo pequenas alterações aos regulamentos das praças públicas de propriedade privada, aprovados em outubro de 2007. A intenção era aprimorar o texto de 2007 para garantir a criação de praças públicas em áreas de propriedades privadas que fossem convidativas, abertas, visíveis e acessíveis. Para isso, as alterações procuram esclarecer alguns padrões e adicionar novas disposições para a melhoria da qualidade e da utilização das praças públicas, como permitir maior circulação de pedestres, garantir a visibilidade de toda a praça e promover espaços públicos atrativos e bem conservados.

Em 6 de maio de 2009, a Comissão de Planejamento Urbano aprovou a alteração de texto com algumas modificações, que deveriam esclarecer ou corrigir termos utilizados, entre eles, a Seção de 37-78, que institui a correta referência de "praça pública", ao invés de "praça urbana". A partir de 10 de junho de 2009, a Câmara Municipal aprovou a Alteração do Texto de Acompanhamento de Praça Pública (Public Plaza Follow-up Text Amendment), cujas mudanças estão em vigor.

A regulamentação para os projetos de novas praças públicas de propriedade privada é orientada atualmente por quatro princípios de projeto:

- aberta e convidativa a partir da calçada: a praça deve ser visualmente interessante e facilmente vista da rua, deixando evidente que é uma área aberta, um espaço público. Os assentos devem ser facilmente visíveis e com caminhos generosos; 
- acessível: a praça deve ser preferencialmente localizada no mesmo nível que a calçada para incentivar o acesso fácil por todos os transeuntes. A circulação de pedestres deve ser incentivada por um percurso agradável e racional de caminhos;

- qualidade nos espaços para assentos: a praça pública deve acomodar uma variedade de lugares bem concebidos e confortáveis para pequenos grupos ou indivíduos, que podem incluir cadeiras fixas e móveis, arquibancadas e muretas largas e baixas;

- sentimento de proteção e segurança: a praça pública deve ser orientada para a rua e ser visualmente ligada a esta, para evitar qualquer sensação de isolamento. Deve ser bem iluminada e conter caminhos de fácil acesso (ZONING Resolution, 2012).

Atualmente a organização Advocates for Privately Owned Public Space (APOPS) trabalha com o objetivo de revigorar os POPS existentes a partir de um trabalho conjunto que envolve os cidadãos, os proprietários dos POPS, os administradores públicos e as associações de bairros, fortalecendo os bons espaços públicos e propondo melhorias aos espaços sem qualidade. A organização administra um site que fornece informações e recebe comentários, sugestões e proposições para a melhoria dos espaços públicos de propriedade privada.

Kayden (2011), um dos fundadores da APOPS, tem defendido a criação de uma nova figura no cenário de gestão dos POPS, que passasse a funcionar como um administrador independente ou curador responsável por promover a utilização ativa dos espaços, para garantir que sejam criados legalmente, a partir da bonificação, e promovam melhorias constantes e atividades educacionais.

Apesar de tantas revisões e atualizações, os projetos dos espaços públicos dos POPS ainda não são de forma participativa, através da qual os cidadãos poderiam auxiliar nos processos de decisões, no que diz respeito a usos, programas e equipamentos, de forma que o projeto atendesse aos anseios e necessidades dos futuros usuários. A introdução de algum tipo de participação traria fomentos respeitáveis para o aumento da apropriação popular desses espaços.

\section{OS POPS DA PARK AVENUE EM NOVA YORK}

A Park Avenue é uma via do bairro Midtown, em Manhattan. Trata-se de uma das avenidas planejadas no plano de arruamento de 1811, elaborado a partir de uma proposta de John Randel e estabelecido pela New York State Legislature. Compreende uma grade ortogonal dividida em onze avenidas e 155 ruas, que configuram a morfologia urbana da ilha. A área selecionada para desenvolvimento desta pesquisa é um segmento da Park Avenue onde estão localizados dois exemplos significativos de espaços de uso coletivo em lotes privados: a praça em frente ao edifício Seagram Building e a marquise coberta do edifício Lever House. 
O trecho em estudo da Park Avenue, entre as ruas E48th St e E59th St, possui dezoito espaços de uso coletivo, todos de propriedade privada, que compreendem: treze espaços coletivos descobertos (praças) e cinco espaços coletivos cobertos (galeria, átrio, passagem). A área de levantamento de dados da região compreende 260.758,27 m². Os dezoito espaços de uso coletivo somam área de 18.606,76 $\mathrm{m}^{2}$, o que corresponde a 7,14\% da área do levantamento (figura 8).

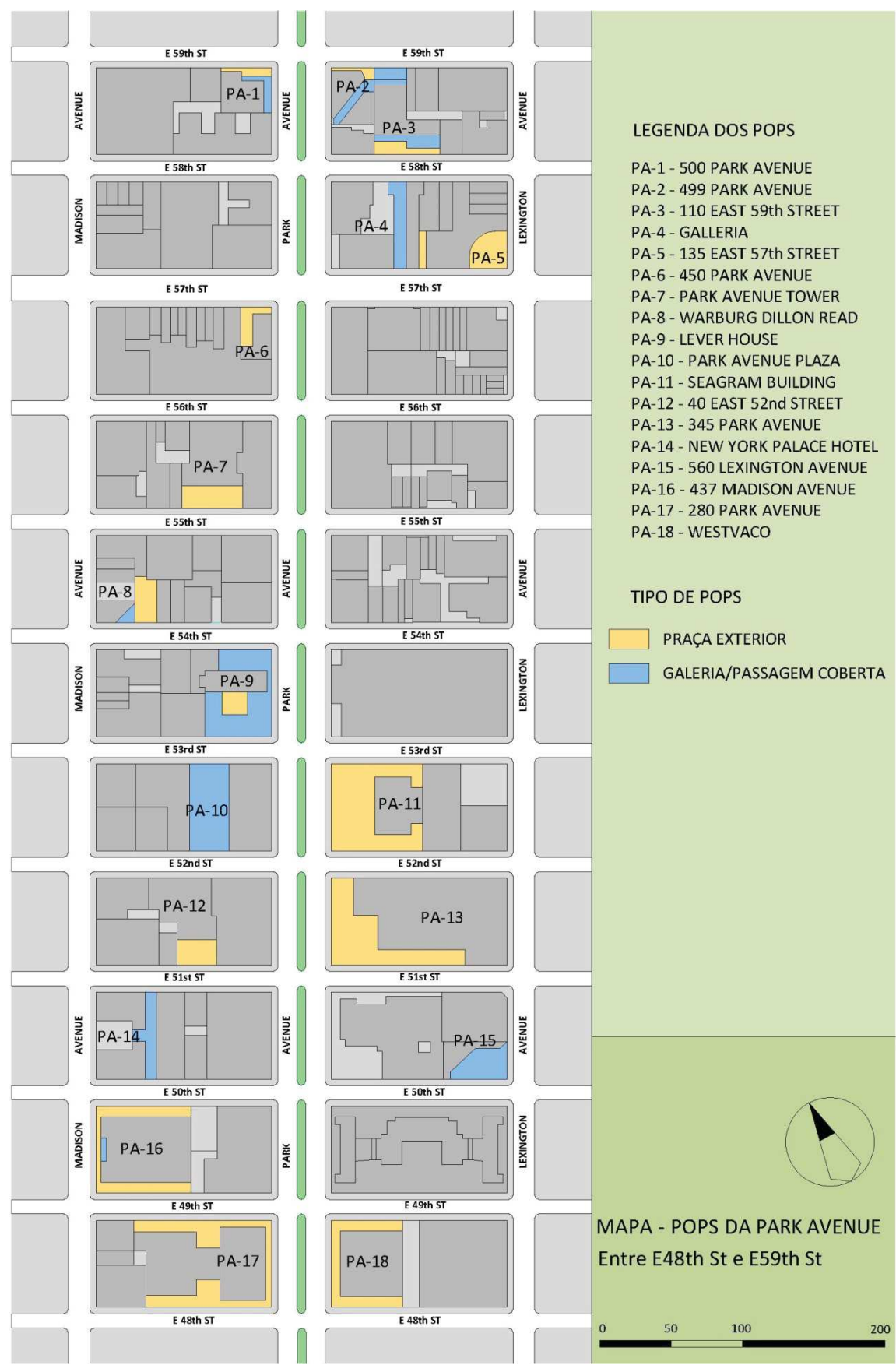

Figura 8 Mapa de áreas de espaços de uso coletivo da Park Avenue no trecho entre a E 48th St e E 59th St. Fonte: Mapa produzido sobre imagem Google Earth, 2016, por Luciana Monzillo de Oliveira, 2016. 
Dos dezoito POPS, apenas três não usaram o sistema de bonificação: o edifício Lever House, o Seagram Building e o 500 Park Avenue. O trecho tem 36 edifícios construídos após a aprovação da Resolução de Zoneamento de 1961, sendo que quinze utilizaram a bonificação, ou seja, 41\%. Em cada um dos dezoito espaços coletivos existentes nesse trecho, foram avaliados parâmetros baseados na metodologia de Gehl (2006) para as qualidades dos espaços de uso público relacionadas aos atos de: acessar (facilidade ou não de acesso a espaço público), ver (visibilidade entre o interior do espaço público e o exterior) e permanecer (a existência de assentos). A partir desses parâmetros, realizaram-se o levantamento de dados e a verificação nos dezoito espaços coletivos identificados no trecho escolhido. Foram definidas as seguintes categorias:

- acessibilidade: o espaço está em nível com a calçada e é facilmente acessado pelo pedestre, sem barreiras físicas ou visuais;

- visibilidade: o espaço é facilmente visualizado pelo pedestre, e uma vez dentro do espaço coletivo, é possível manter contato visual com a via pública;

- permanência: o espaço tem assentos disponíveis, de fácil e rápido acesso ao usuário.

Os dados observados no local para os dezoito espaços foram numerados e legendados de PA-1 até PA-18 (tabela 1):

\begin{tabular}{l|l|l}
\hline $\begin{array}{l}\text { Legenda } \\
\text { do mapa }\end{array}$ & $\begin{array}{c}\text { Ano de } \\
\text { inaugur. }\end{array}$ & \multicolumn{1}{|c}{ Denominação dos POPS } \\
\hline PA-1 & 1984 & 500 Park Avenue \\
\hline PA-2 & 1981 & 499 Park Avenue \\
\hline PA-3 & 1969 & 110 East 59th Street \\
\hline PA-4 & 1975 & Galleria \\
\hline PA-5 & 1987 & 135 East 57th Street \\
\hline PA-6 & 1972 & 450 Park Avenue \\
\hline PA-7 & 1986 & Park Avenue Tower \\
\hline PA-8 & 1981 & Warburg Dillon Read \\
\hline PA-9 & 1952 & Lever House \\
\hline PA-10 & 1979 & Park Avenue Plaza \\
\hline PA-11 & 1958 & Seagram Building \\
\hline PA-12 & 1986 & 40 East 52nd Street \\
\hline PA-13 & 1968 & 345 Park Avenue \\
\hline PA-14 & 1978 & New York Palace Hotel \\
\hline PA-15 & 1980 & 560 Lexington Avenue \\
\hline PA-16 & 1968 & 437 Madison Avenue \\
\hline PA-17 & 1968 & 280 Park Avenue \\
\hline PA-18 & 1966 & Westvaco \\
\hline
\end{tabular}
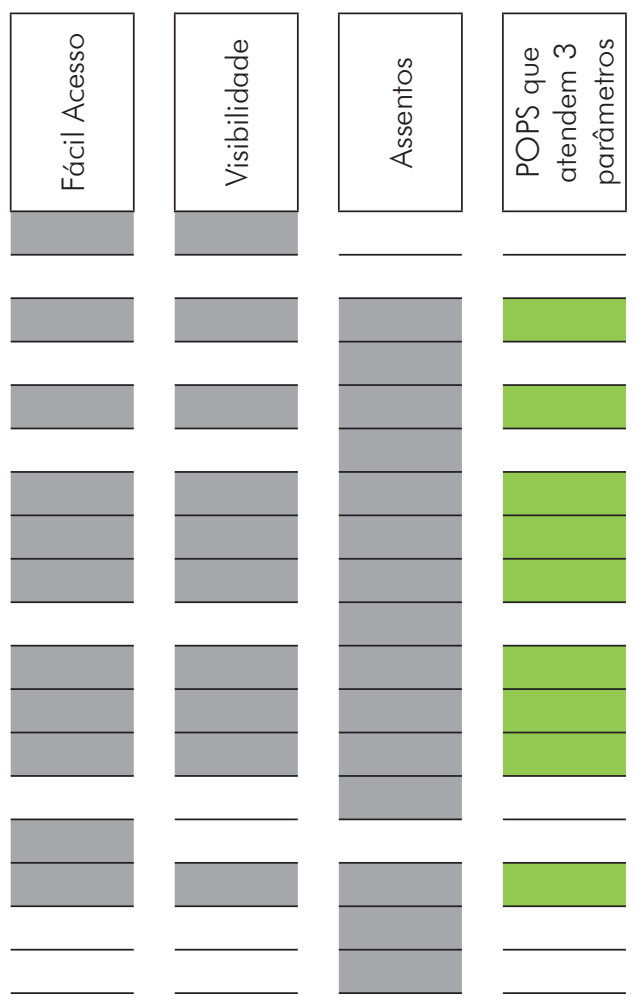

Tabela 1 Em cinza estão identificadas as categorias que foram registradas nos POPS analisados do trecho da Park Avenue; em verde, destacados os POPS onde foram identificados e registrados os três parâmetros analisados como satisfatórios para os espaços públicos de propriedade privada. Fonte: Elaborado pelas autoras. 
A análise dos dados indica que dos dezoitos POPS, nove espaços atendem aos três parâmetros apontados por Gehl (2006) como boas condições para os espaços para uso público. Todos esses espaços são praças, com acesso diretamente a partir das calçadas, sem barreiras arquitetônicas ou visuais. Apenas a marquise do Lever House é uma área parcialmente coberta (figura 9).

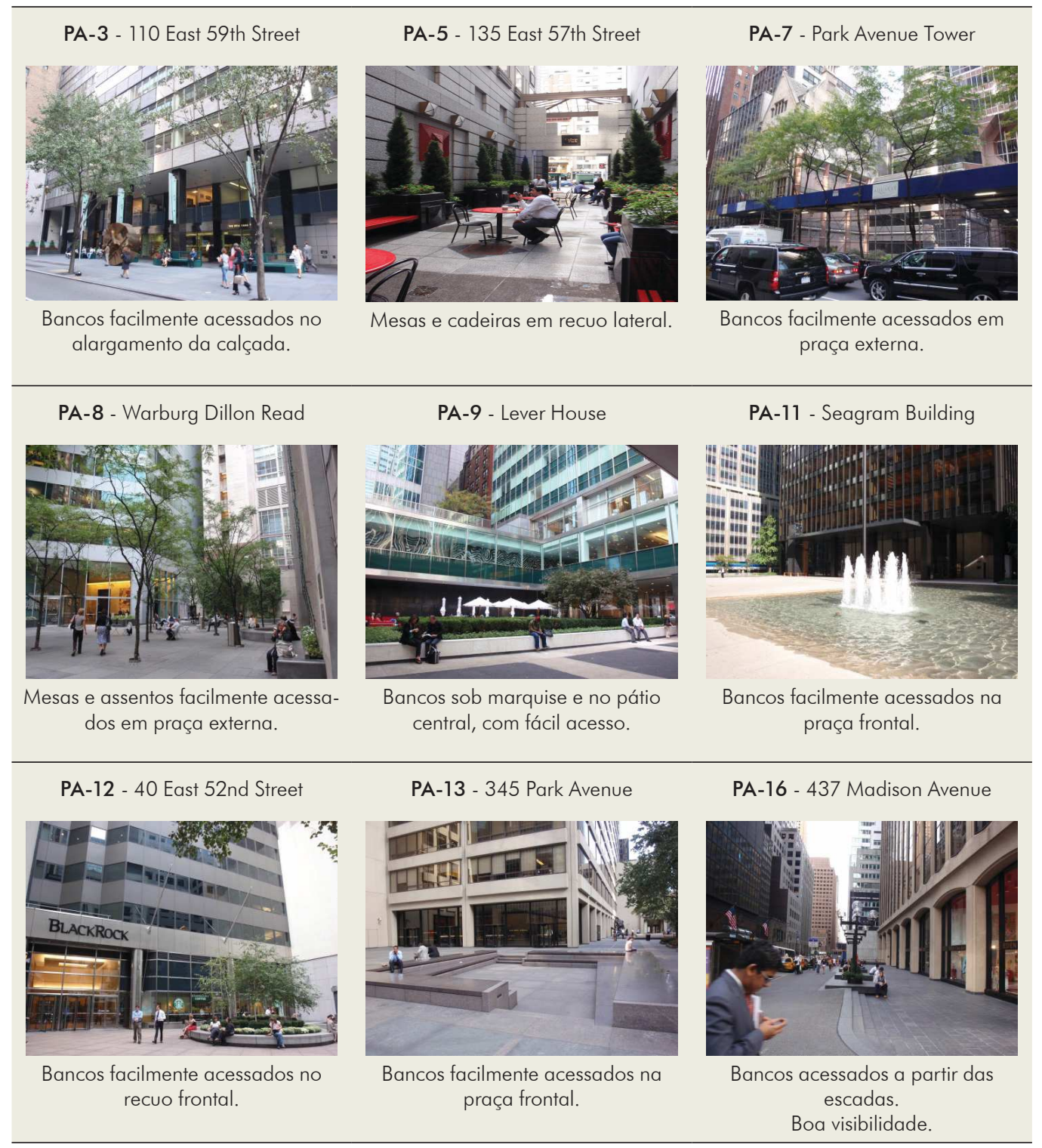

Figura 9 Nove POPS da Park Avenue, onde há boa qualidade em relação à facilidade de acesso, visibilidade e assentos para permanência da população.

Fotos: Luciana Monzillo de Oliveira, 2013.

Cada um dos demais nove POPS não atende pelo menos um dos parâmetros de Gehl (2006), e, portanto, não foram considerados plenamente satisfatórios como espaços para atração e apropriação pelos usuários. Alguns não têm assentos para permanência da população, outros possuem barreiras arquitetônicas, como escadas 
ou portas (figura 10). Os espaços internos, galerias e arcadas ou passagens internas entre duas ruas através do edifício são áreas reconhecidas predominantemente pelos moradores e usuários frequentes da região, tornando difícil a identificação da área como de uso público pelos turistas ou pedestres ocasionais.

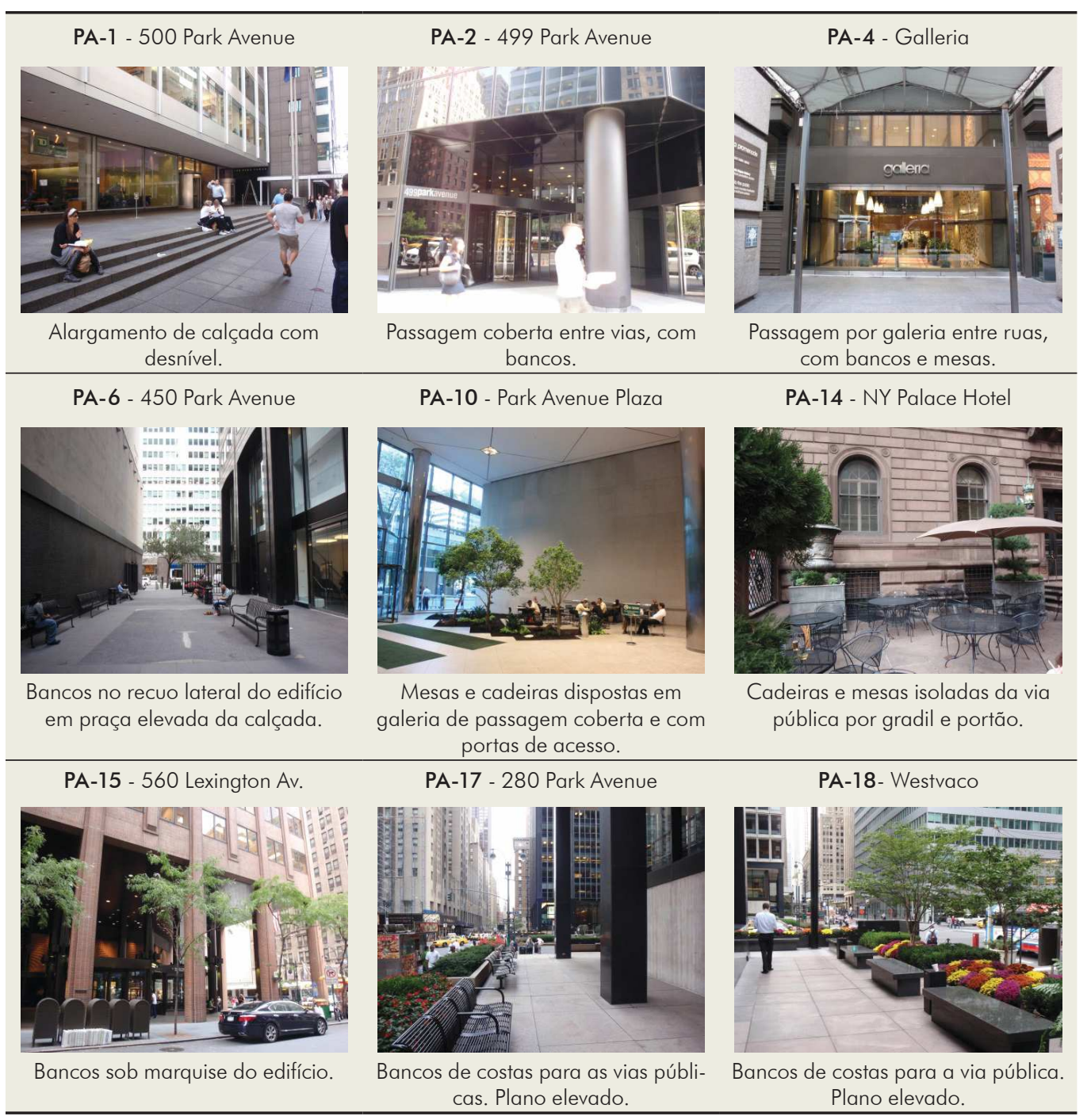

Figura 10 Nove exemplos de POPS da Park Avenue, com carência de qualidades em relação à facilidade de acesso, visibilidade e assentos para permanência da população.

Fotos: Luciana Monzillo de Oliveira, 2013.

Além das qualidades físicas, a análise dos espaços livres de edificações, resultantes da utilização do sistema de incentivo para criação dos espaços públicos de propriedade privada nos lotes do trecho analisado, apresentou diferentes configurações de paisagens. Por exemplo, no trecho entre as ruas E57th St. e E59th St. (figura 11), onde os edifícios foram construídos majoritariamente antes da Resolução de Zoneamento de 1961, a ocupação do lote no embasamento dos edifícios é praticamente de toda a área do terreno, o que não permitiu a existência de áreas livres de edificações. 


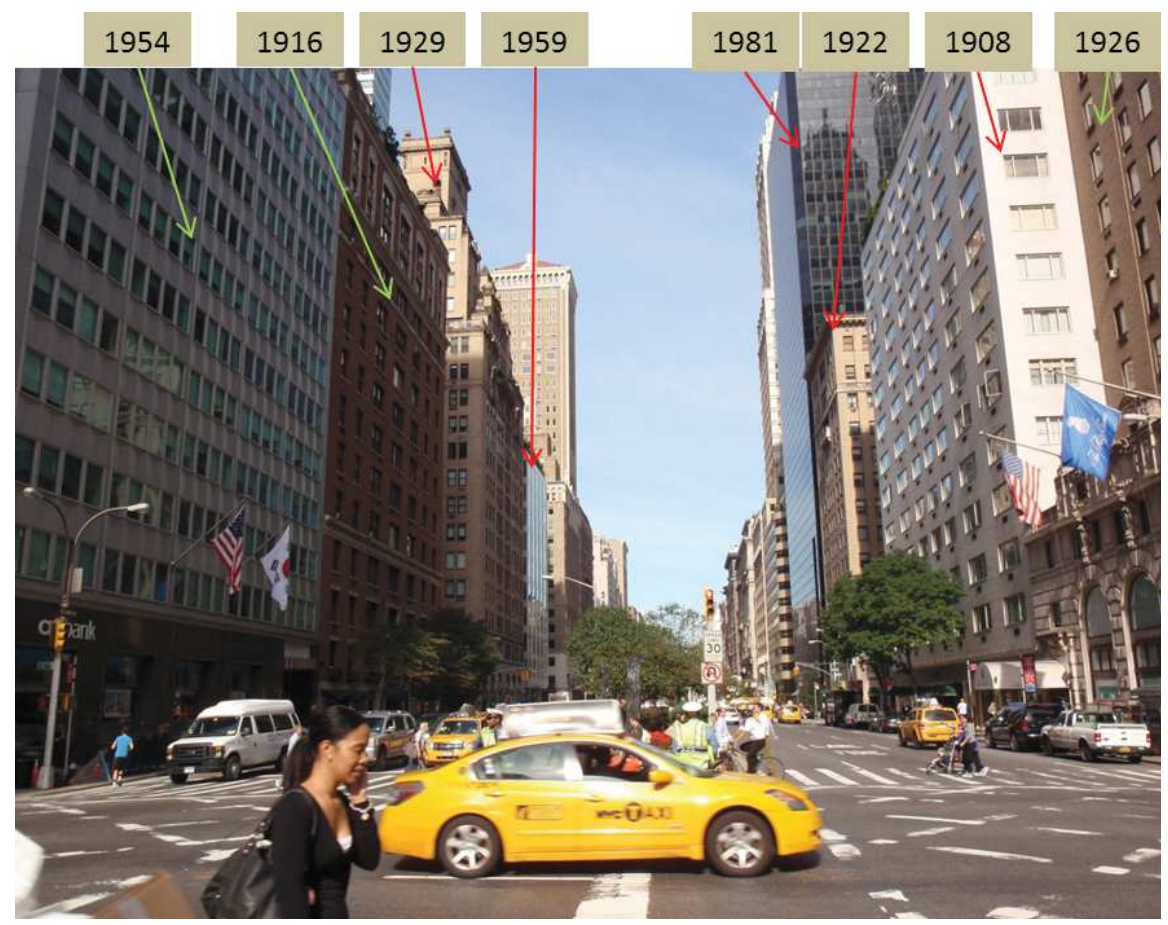

Figura 11 Vista da Park Avenue para o Norte, a partir do cruzamento com a E57th St, onde os edifícios construídos antes da Resolução de Zoneamento de 1961 ocupam todo o lote, não restando espaço livre no embasamento. Datas da inauguração dos edifícios a partir de Zola (2017).

Foto: Luciana Monzillo de Oliveira, 2016.

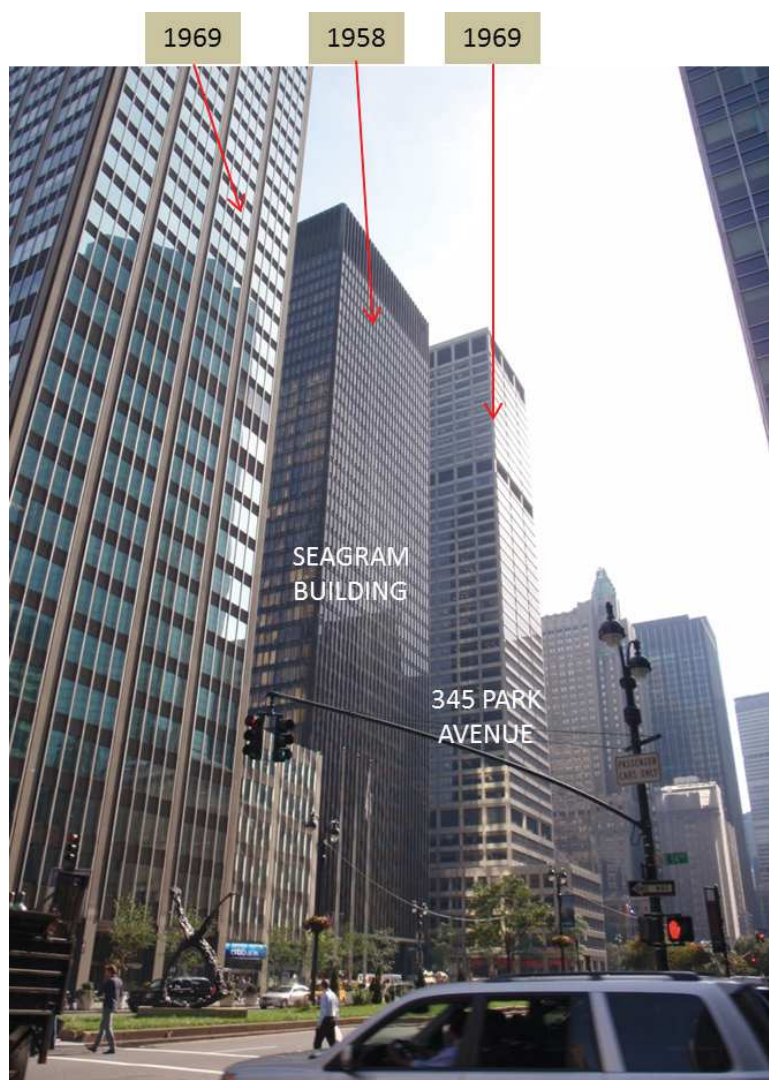

Figura 12 Vista da Park Avenue em direção ao Sul, a partir da E54th St, onde é possível observar o recuo frontal do edifício Seagram Building, ao centro, e do edifício à direita 345 Park Avenue. Datas da inauguração dos edifícios a partir de Zola (2017).

Foto: Luciana Monzillo de Oliveira, 2016. 
Em outro trecho, entre as ruas E54th St. e E51th St. (figura 12), a conjunção da praça do Seagram Building, juntamente com a praça do edifício 345 Park Avenue, que utilizou o sistema de bonificação, criaram uma paisagem aberta e convidativa para os pedestres usufruírem das praças.

\section{CONSIDERAÇÕES FINAIS}

Nova York apresentou um processo de verticalização e adensamento em determinados distritos, que intensificou o agrupamento e circulação de pessoas em setores da cidade. Como resposta à necessidade de aeração e insolação nas vias públicas das regiões mais adensadas, juntamente com a premência de oferecer áreas para uso público em regiões muito valorizadas, o governo municipal incentivou a criação de espaços coletivos dentro dos lotes privados, fornecendo como contrapartida a permissão para construção de área de edificação além do permitido pelas restrições urbanísticas.

A transferência da provisão e manutenção dos espaços para uso coletivo - do poder público para o poder privado - induziu a proliferação de espaços públicos de propriedade privada, os denominados POPS. Estes são resultantes da colaboração mútua entre as duas esferas, por meio de mecanismos pelos quais os governos municipais incentivam os empreendedores, que os utilizam, sendo os resultados benéficos para todos. Quando o investidor particular está disposto a criar espaços acessíveis ao público dentro de seus projetos, e ao mesmo tempo obter benefícios, essas parcerias podem suprir necessidades de regiões das cidades que nem sempre estão bem providas de espaços públicos (YOON; SRINIVASAN, 2015).

A adoção do sistema de bonificação, no trecho analisado, por $41 \%$ dos empreendedores que construíram edifícios a partir da Resolução de Zoneamento de 1961, permite concluir que se trata de um sistema que interessa ao investidor privado. Por outro lado, apenas $50 \%$ dos POPS obtiveram qualidades satisfatórias, segundo os preceitos de Gehl (2006).

Entre os outros $50 \%$ dos POPS que não obtiveram resultados adequados, a maior parcela é composta por arcadas, galerias e passagens que são de difícil identificação e acesso aos pedestres, o que não atende a premissa fundamental do espaço para uso público: ser convidativo ao usuário. Os espaços de uso público fechados nos térreos dos edifícios não contribuem para a paisagem urbana, pois não geram espaços livres de edificações, não colaborando para a insolação e aeração das vias e passeios públicos. Por outro lado, as praças corporativas externas podem contribuir para as qualidades visuais e de conforto ambiental e são facilmente visualizadas e acessadas pela população.

As visitas para levantamento de dados permitiram observar diferentes atividades desenvolvidas pelas pessoas: contemplação, leitura, conversas em pequenos grupos, descanso, alimentação, entre outras. A apropriação desses ambientes coletivos pelos cidadãos, que podem até desenvolver o sentimento de pertencimento, acontece quando há facilidade de acesso, boa visibilidade entre o espaço coletivo e a calçada e mo- 
biliários de qualidade que permitam a permanência da população nos espaços para uso público. As cidades com espaços coletivos de qualidade convidam as pessoas a sair de seus ambientes privados, a conviver e a compartilhar a vida pública. Devido a tantos benefícios, a criação de mais espaços públicos tornou-se uma das premissas do planejamento e do projeto urbanos no século XXI.

Algumas cidades brasileiras de grande e médio porte vêm apresentando uma pulverização de novas centralidades em territórios urbanos de características fragmentárias, o que torna necessário ampliar as discussões e propor políticas públicas que fomentem a provisão de áreas para uso coletivo que promovam as qualidades da paisagem urbana.

\section{REFERÊNCIAS BIBLIOGRÁFICAS}

APOPS. Advocates for Privately Owned Pubic Spaces. History. Disponível em: <http://apops.mas.org/about/ history/>. Acesso em: 17 out. 2016.

BANERJEE, Tridib. The future of public space: beyond invented streets and reinvented places. In: CARMONA, Matthew; TIESDELL, Steve (Ed.). Urban design reader. Oxford: Elsevier, 2007.

CAMPOS, A. C. A cidade, espaço de convivência. Revista Bibliográfica de Geografía y Ciencias Sociales, Universidad de Barcelona. Biblio 3W, Vol. IX, n 546, 15 nov. 2004. Disponível em: <http://www.ub.es/geocrit/ b3w-546.htm>. Acesso em: 2 jun. 2016.

CENSUS Bureau. U.S. Department of Commerce. 2010. Disponível em: <www.census.gov/>.

Acesso em: 15 ago. 2016

GEHL, Jan. La humanización del espacio urbano: la vida social entre los edificios. Barcelona: Reverté, 2006.

GOLDBERGER, P. The rise of private city. In: CARMONA, Matthew; TIESDELL, Steve (editors). Urban design reader. Oxford: Elsevier, 2007.

KAYDEN, Jerold S. Privately owned public space: the New York City experience. New York: The New York City Department of City experience, 2000.

. Meet me at the plaza. 19 out. 2011 In: New York Times. Disponível em: <http://www.nytimes. $\overline{c o m} / 201$ 1/10/20/opinion/zuccotti-park-and-the-private-plaza-problem.html>. Acesso em: 15 dez. 2015.

MACEDO, Silvio Soares. Paisagismo brasileiro na virada do século: 1990-2010. São Paulo: Edusp; Campinas: Unicamp, 2012.

MADANIPOUR, Ali. Public and private spaces of the city. Nova York: Routledge, 2003.

NEW York City. City of New York. 2016. Privately Owned Public Space: history - inauguration of the Program. Disponível em: <https://wwwl .nyc.gov/site/planning/plans/pops/pops-history.page>. Acesso em: 5 out. 2016.

SOLÁ-MORALES, Manuel de. Espaços públicos, espaços coletivos. In: Os centros das metrópoles: reflexões e propostas para uma cidade democrática do século XXI. São Paulo: Associação Viva O Centro. 2001.

UNITED Nations Human Settlements Programme. UN-HABITAT. Public Spaces for all. 2015. Disponível em: <http://unhabitat.org/public-spaces-for-all-2/>. Acesso em: 7 nov. 2016.

YOON, Heeyeun; SRINIVASAN, Sumeeta. Are they well situated? Spatial analysis of Privately Owned Public Space, Manhattan, New York City. In: Urban Affairs Review, vol. 51 (3), 2015, p. 358-380.

ZOLA Zoning \& Land Use. New York City Planning. Disponível em: <http://maps.nyc.gov/doitt/nycitymap/ template? applicationName =ZOLA>. Acesso em: 20 mar. 2017.

ZONING Resolution of the City of New York, City Planning Commission, 2012. Disponível em: <http://www.nyc. $\mathrm{gov} / \mathrm{html} / \mathrm{dcp} / \mathrm{pdf} /$ zone/allarticles.pdf>. Acesso em 22 jan. 2016. 